\title{
Lizija: Govor v obrambo Eratostenovega umora
}

\author{
Prevod Polonca Zupančič
}

Ta govor je Lizija napisal za Atenca Evfileta, ki se je na sodišču zagovarjal zaradi uboja Eratostena iz Oe v Atiki - Evfilet je namreč izvedel, da slednji prešuštvuje z njegovo ženo, nato pa ga je zalotil pri samem dejanju in ga na mestu ubil. Eratostenovi sorodniki so proti Evfiletu sprožili sodni postopek in ga obtožili načrtnega umora, verjetno pa so v obtožbi navedli tudi, da je bilo prešuštvo le pretveza, saj naj bi se hotel Evfilet v resnici poslužiti Eratostenovega premoženja. Skoraj zagotovo so poskušali dobiti primer z zatrjevanjem, da je bil Eratosten ubit ob ognjišču, ki je veljalo za sveto. Evfilet je uboj sicer priznal, zavrnil pa je obtožbe o načrtovanem maščevanju.

$\mathrm{V}$ uvodnem nagovoru porotnikov se Evfilet sklicuje na splošen odpor do prešuštva po vsej Grčiji in jih prosi, naj njegov primer obravnavajo tako, kakor bi sodili samim sebi, če bi se znašli v tej situaciji (1-5). Pri tem zatrdi, da za uboj Eratostena ni imel nobenega drugega motiva, pač pa se mu je v skladu z zakonom le maščeval. ${ }^{1}$ Sledi osrednji del (6-26), v katerem Evfilet pojasni razmere pred ubojem: zakon naj bi bil stabilen, zato ni sprva ničesar posumil, po rojstvu otroka pa je ženi že povsem zaupal in ji celo prepustil v skrb vse svoje zadeve. Po materini smrti se je to spremenilo, kajti na pogrebu je njegovo ženo opazil Eratosten, jo po posredovanju hišne služabnice napeljal k prešuštvu ter se pričel na skrivaj dobivati z njo v Evfiletovi lastni hiši. Evfilet naj bi za vse te dogodke izvedel šele naknadno, nekega dne je namreč $\mathrm{k}$ njemu je namreč pristopila stara ženica, služabnica druge ženske, s katero je imel Eratosten razmerje, in mu povedala, kaj se dogaja. Šele ko je Evfilet zagrozil domači služkinji, je ta potrdila starkino zgodbo in mu obljubila, da mu bo pomagala prešuštnika ujeti. Čez nekaj dni ga je res obvestila, da je moški zopet v hiši,

1 Evfilet se sklicuje na Drakonov zakon, ki je možu dovoljeval ubiti prešuštnika, če uboja ni načrtoval vnaprej, pač pa je prešuštnika zalotil pri dejanju in na samem mestu izvršil maščevanje. 
Evfilet pa se je tiho izmuznil ven, nabral nekaj prijateljev, Eratostena zalotil pri dejanju in ga ubil. V argumentaciji, ki sledi (27-46), Evfilet dokazuje, da Eratostena ni zasledoval niti ga ni ubil načrtno, ampak se je spontano odzval na razvoj dogodkov, pri tem pa med njim in Eratostenom ni bilo nobenih drugih zamer, saj se do nedavnega nista niti poznala. Poleg tega je Evfilet le sledil temu, kar velevajo zakoni, zato ni zagrešil zločina, pač pa je izvršil pravico. To Evfilet znova izpostavi v zaključku (47-50), kjer še enkrat izjavi, da je deloval v javno dobro s tem, ko je sledil predpisanim zakonom.

(1) Zelo bi cenil, možje, če bi mi glede tega primera razsodili tako, kakor bi razsodili sami sebi, če bi utrpeli takšne stvari. Dobro namreč vem - če bi glede drugih imeli enako mnenje, kakršnega imate glede samih sebe, ne bi bilo nikogar, ki se ne bi razsrdil nad temi dogodki, ampak bi vsi trdili, da so kazni za tiste, ki počnejo takšne stvari, še premajhne. (2) Na to ne bi tako gledali samo vi, pač pa ljudje po celotni Grčiji: kajti le v primeru tega prekrška je tako v vladavini ljudstva kakor v oligarhiji šibkejšim dana ista pravica, da se maščujejo najbolj vplivnim, tako da tudi najnižjega izmed njih doleti isto kakor najvišjega - zato, možje, ker vsi ljudje menijo, da je ta prestopek res najhujši. (3) Verjamem, da ste vsi enakega mnenja, kako visoka naj bo kazen, in da nikomur ni tako malo mar, da bi mislil, da je potrebno krivce oprostiti, oziroma bi verjel, da si povzročitelji takšnih prestopkov zaslužijo le majhne kazni. ${ }^{2}$

(4) Možje, menim, da sem vam dolžan pojasniti, kako je Eratosten prešuštvoval z mojo žensko, jo izpridil, onečastil moje otroke, mene samega pa osramotil s tem, da je vstopil v mojo lastno hišo; pri tem med mano in onim ni bilo nobene sovražnosti razen te, tako nisem ravnal zaradi denarja $\mathrm{z}$ namenom, da bi iz reveža postal bogataš, niti zaradi kake druge koristi, ampak le iz maščevanja, ki pa je bilo v skladu z zakoni. ${ }^{3}$ (5) Zatorej vam bom po vrsti pojasnil vsa svoja dejanja, pri tem pa ne bom ničesar izpustil, ampak bom govoril po resnici: menim namreč, da mi pomaga le to, da vam lahko povem o vsem, kar se je zgodilo.

(6) Atenci, potem ko sem se sklenil oženiti in sem pripeljal žensko v hišo, sem nekaj časa ravnal tako, da je sicer nisem nadlegoval, vendar tudi ni bilo v njeni moči vse, kar je želela početi; pazil sem jo, kolikor sem lahko, in bil toliko pozoren, kolikor je še bilo prav. Ko pa mi je rodila otroka, sem ji že povsem zaupal in ji prepustil vse svoje zadeve, saj sem menil, da je zveza karseda trdna. (7) Oh, Atenci, sprva je bila zares najboljša med vsemi ženami! Bila je namreč

2 Verjetno gre prej za retorični prijem kakor historično dejstvo - s prikazovanjem prešuštva kot vsesplošno nesprejemljivega in s sklicevanjem na splošni moralni čut poskuša Evfilet vplivati na porotnike in doseči, da bi mu bili že od vsega začetka naklonjeni.

3 Evfilet ni zanikal uboja, pač pa je poskušal dokazati, da je bil ta upravičen in v skladu z zakoni. Lizija je pri tem postopal zelo taktno, saj je glavni del govora oblikovan tako, da natančno prikaže razvoj dogodkov pred ubojem, medtem ko je samo dejanje uboja le omenjeno - poudarek je torej na Eratostenovem zločinu, ta je v vlogi obtoženca, Evfilet pa se prikaže kot razsodnik, ki nad njim izvrši pravično kazen. 
izredna in varčna gospodinja - za vse je marljivo poskrbela. Toda ko mi je umrla mati, je ta s svojo smrtjo postala vzrok vsega slabega, (8) kajti ko jo je moja ženska spremljala na pogrebu, jo je zagledal ta moški, ki jo je sčasoma pokvaril: prežal je na služabnico, ki je hodila na trg, prek nje nagovoril ženo in jo tako pogubil. ${ }^{4}$

(9) Najprej pa tole, možje (kajti povedati vam moram tudi o tem): moja hiša je iz dveh nadstropij, ženski prostori zgoraj pa so razporejeni enako kakor moški prostori spodaj. Ko se nama je rodil otrok, ga je mati dojila, da pa ne bi bila v nevarnosti zaradi sestopanja po stopnicah vsakič, ko bi ga bilo potrebno umiti, sem jaz živel zgoraj, ženske pa spodaj. (10) Kmalu je bilo že povsem običajno, da je včasih žena odhajala dol, češ da gre spat k otroku, da bi ga lahko dojila in da ta ne bi jokal. To se je dogajalo precej dolgo, toda jaz nisem ničesar posumil, ampak sem bil tako nespameten, da sem verjel, da je moja žena najbolj spodobna izmed vseh v državi. (11) Minilo je nekaj časa, možje. Ko sem se nekoč nepričakovano vrnil s polja, je po večerji pričel otrok jokati in se čemeriti, ker ga je služabnica nalašč vznejevoljila z namenom, da bi se tako obnašal: tisti človek je bil namreč v hiši! ${ }^{5} \mathrm{Za}$ vse to sem sicer izvedel šele kasneje. (12) In velel sem ženi, naj gre in podoji otroka, da bi prenehal z jokom. Ta pa sprva ni hotela, češ da je tako vesela, da me spet vidi doma po dolgem času, brž ko pa sem se pričel jeziti in sem ji velel, naj pri priči odide, je rekla: »Seveda, da boš ti poskušal pri dekli, ki si se je pijan lotil že prej! « ${ }^{6}$ (13) Jaz sem se smejal, ona pa je vstala, odšla, zaprla vrata in jih kakor v šali zapahnila. Jaz pa se nisem posebej zmenil za nič od tega niti nisem ničesar posumil, ampak sem zadovoljno počival po svoji vrnitvi s polja. (14) Proti jutru je prišla nazaj in odklenila vrata, ko pa sem jo spraševal, zakaj so vrata ponoči škripala, je rekla, da je bakla pri otroku ugasnila in jo je dala ponovno prižgati pri sosedih. ${ }^{7}$ Jaz sem molčal in verjel, da je to res. Toda možje, zdelo se mi je, da si je nalepotičila obraz, čeprav še ni minilo trideset dni, odkar je umrl njen brat $^{8}$ - vendar nisem ničesar rekel glede tega, ampak sem molče odšel ven.

(15) Po tem, možje, ko je preteklo nekaj časa in mi je lastna nesreča ostala prikrita, pristopi k meni neka starka, ki jo je skrivaj odposlala ženska, s

4 Evfilet krivdo za prešuštvo zvrača na Eratostena, saj naj bi bila njegova žena pred tem krepostna in zgledna, šele razmerje $\mathrm{z}$ njim pa naj bi jo moralno pokvarilo.

5 Po eni razlagi naj bi na ta način služabnica dala ženi vedeti, da je Eratosten ravnokar prišel, po drugi pa naj bi bil Eratosten ob Evfiletovem prihodu že v hiši, služabnica pa naj bi ženi po njenih lastnih navodilih na ta način omogočila, da se pod pretvezo odpravi v spodnje prostore.

6 Zanimiv je kontrast med dolžnostmi žene in moža: medtem ko se od žene pričakuje, da bo možu povsem zvesta, pa to očitno zanj ne velja. Seveda pa ji to služi tudi kot prikladen izgovor, da odvrne pozornost od sebe in se na ta način zavaruje pred sumničenjem.

7 Ta detajl pojasnjuje, zakaj je morala odpreti »oboje vrat « oziroma »oba vhoda - žena se je morda to navedla kot razlog za odhod ven, morda pa je dejansko sama ugasnila baklo in pod to pretvezo odšla k sosedom ter hkrati svojemu ljubimcu omogočila nemoten odhod.

8 V znak žalovanja se atenske ženske nekaj časa po pokopu niso ličile. Nenavadno je, da je Evfilet ličilo opazil šele naslednje jutro, ne pa že prejšnji večer ob obedu, prav tako pa je tudi s strani žene precej tvegano, da se je pred možem prikazala naličena, saj bi ta zlahka kaj posumil. 
katero je oni človek prav tako prešuštvoval, kakor sem pozneje slišal. Ta ženska se je jezila in menila, da se ji dela krivica, ker ta ni več tako pogosto hodil k njej; skrbno ga je opazovala, dokler ni izvedela, kaj je bil vzrok za to. (16) Potem ko je starka nekaj časa oprezala okoli moje hiše, se mi je približala in rekla: »Evfilet, ne misli, da sem prišla $\mathrm{k}$ tebi iz kake radovednosti, pač pa nama je človek, ki sramoti tako tebe kakor tvojo ženo, slučajno skupen sovražnik. Če boš prijel tisto služkinjo, ki hodi na trg in vama streže, in jo boš zaslišal, boš vse izvedel!« Rekla je še: »Eratosten iz Oe je ta, ki to počne - uničil pa ni samo tvoje žene, ampak tudi mnoge druge - kajti to je njegov posel.« (17) To je rekla, možje, in odšla, jaz pa sem se v trenutku vznemiril, vse mi je prihajalo na misel in bil sem poln sumničenj, kajti premišljeval sem o tem, kako sem bil zaklenjen v sobi, se spominjal, da so v oni noči škripala notranja in zunanja dvoriščna vrata - kar se ni še nikdar zgodilo - in da se mi je zazdelo, da se je žena nalepotičila. Vse to mi je prihajalo na misel in bil sem poln sumničenj.

(18) Ko sem se vrnil domov, sem ukazal služabnici, naj me spremlja na trg, ko pa sem jo privedel k enemu izmed prijateljev, sem ji povedal, da vem za vse, kar se dogaja v hiši. Rekel sem: »Lahko izbereš katero koli izmed dvojega želiš: ali biti prebičana, vržena v mlin in nikdar prosta takšnih nadlog, ${ }^{9}$ ali pa - če boš povedala vse po resnici - ne utrpeti nobenega zla, pač pa dobiti od mene celo odpuščanje za storjeno. O ničemer ne laži, ampak povej vse po resnici!« (19) Ona je sprva sicer tajila in velevala, naj počnem, kar hočem, češ da ničesar ne ve. Ko pa sem ji omenil Eratostena in ji rekel, da je bil ta tisti človek, ki je obiskoval ženo, se je prestrašila ob misli, da vem popolnoma vse. Takoj se je vrgla pred moja kolena in ko je od mene dobila zagotovilo, da ne bo utrpela ničesar slabega, (20) ga je najprej obtožila tega, da je po pogrebu pristopil k njej, nato pa je povedala, kako mu je naposled poročala, kako se mu je žena sčasoma pustila pregovoriti, na kakšne načine mu je omogočila vstop v hišo in kako je na praznik Tezmoforij, ${ }^{10}$ ko sem bil jaz na podeželju, šla $\mathrm{k}$ svetišču skupaj z njegovo materjo. Natančno je poročala tudi o vseh drugih stvareh, ki so se zgodile. (21) Ko je vse to povedala, sem ji dejal: »Da mi ne bi kdo izvedel za to! V nasprotnem primeru ne bo veljalo nič izmed tega, kar si sklenila $\mathrm{z}$ mano. Hočem pa tudi, da mi vse to razkriješ med samim dejanjem, kajti ne potrebujem besed, pač pa mora biti dejanje razkrito, če je s tem res tako."

(22) Pristala je, da bo to tudi storila. Po tem je minilo štiri ali pet dni ... kakor vam bom dokazal s tehtnimi dokazi. Toda najprej bi rad povedal, kaj se je zgodilo zadnji dan. Sostrat je moj tovariš in prijatelj. Po sončnem zahodu sem ga srečal, ko se je odpravljal s polja, ker pa sem vedel, da ob tem času ne bo našel doma nikogar več izmed bližnjih, sem mu predlagal, naj obeduje

9 V Atenah je bilo dovoljeno mučiti sužnje z namenom, da bi od njih dobili določene informacije.

10 Tezmoforije so bile ene izmed prireditev, ki so se jih udeleževale poročene ženske. Praznovali so jih jeseni, oktobra oziroma novembra, slavje pa je potekalo nekaj dni skupaj. 
$\mathrm{z}$ mano. Prispela sva torej $\mathrm{k}$ meni domov, se povzpela $\mathrm{v}$ zgornji prostor in poobedovala. (23) Po lepo preživetem času je oni hitro odšel, jaz pa sem počival. Nato, možje, pride Eratosten, služabnica pa me je nemudoma prebudi in mi pove, da je v hiši. ${ }^{11}$ Rečem ji, naj pazi na vrata, jaz pa se spustim dol, potiho odidem in dospem $\mathrm{k}$ temu in onemu, pri tem pa sem ene našel doma, drugih pa ne. (24) Potem ko sem jih izmed teh, ki so bili doma, nabral toliko, kolikor je bilo mogoče, sem šel dalje. Iz bližnje trgovine smo vzeli bakle in vstopili - vrata so bila namreč odprta, ker je služabnica poskrbela za to. Odprli smo vrata spalnice in tisti, ki smo vstopili prvi, smo ga še lahko videli, kako leži ob ženi, oni pozneje pa, kako stoji gol na postelji. ${ }^{12}$ (25) Jaz, možje, ga $\mathrm{z}$ udarcem zbijem na tla, mu potegnem roki nazaj za hrbet in zvežem, pri tem pa sprašujem, kako si drzne priti v mojo hišo. Oni je priznal svojo krivdo in me rotil, naj ga ne ubijem, ampak si dam izplačati odškodnino, (26) jaz pa sem odvrnil: »Ne bom te ubil jaz, pač pa zakon polis, ki si ga ti prekršil in ga cenil manj kakor užitke ter si se odločil, da boš raje zagrešil ta prekršek proti moji ženski in mojim otrokom, kakor pa se pokoraval zakonom in bil spodoben.«

(27) Tako, možje, je onega doletelo to, kar ukazujejo zakoni v primeru takih, ki počenjajo takšna dejanja. Nismo ga zvlekli sem s ceste niti se ni zatekel k ognjišču, ${ }^{13}$ kakor trdijo tile. Le kako bi se namreč lahko, če pa je v spalnici pretepen takoj padel na tla, jaz sem ga obdal okoli rok, znotraj hiše pa je bilo toliko mož, da jim ne bi mogel ubežati? Imel ni niti orožja ne česa lesenega, sploh ničesar, s čimer bi se lahko branil pred temi, ki so vstopili. (28) Mislim pa, možje, da tudi vi veste, da tisti posamezniki, ki ne ravnajo pravično, ne priznavajo, da sovražniki govorijo resnico, ampak sami lažejo in snujejo takšne stvari z namenom, da bi poslušalcem vzbujali jezo do tistih, ki ravnajo pravično. Najprej pa preberi zakon! ${ }^{14}$

\section{$\mathrm{ZAKON}^{15}$}

(29) Ni ugovarjal, možje, ampak priznaval, da je kriv in me rotil in moledoval, naj ga ne ubijem; bil je pripravljen odplačati odškodnino. Jaz pa nisem soglašal s predlagano odškodnino, ker sem menil, da ima zakon te polis večjo veljavo.

11 Evfilet namenoma poudari, da je spal, ko ga je služabnica prebudila - če bi že prej prijel Eratostena v hiši, bi ostal buden.

12 Ta detajl je pri Evfiletovem zagovoru zelo pomemben, saj služi kot dokaz, da je bil Eratosten zares zasačen pri samem dejanju prešuštva.

13 Ognjišče je veljalo za sveto: ogenj za kuhanje je služil tudi kot medij za komunikacijo z bogovi, zato je bil pod njihovo zaščito vsakdo, ki se je zatekel k ognjišču. Evfilet poudarja, da ni bilo nikakršne možnosti, da bi Eratosten lahko dosegel hišno ognjišče; v tem primeru bi namreč Evfilet $\mathrm{z}$ ubojem zagrešil bogoskrunstvo.

14 V zagovoru je bilo običajno, da se je obtoženi skliceval na določene zakone, vendar pa se jih navadno ni zapisovalo; enako velja za izjave prič.

15 Verjetno je šlo za zakon glede prešuštva. 
Tako sem mu naložil takšno kazen, kakršno ste postavili vi v mnenju, da je najpravičnejša za tiste, ki počenjajo takšne stvari. Priče za vse to, stopite mi gor!

\section{PRIČE}

(30) Preberi mi tudi ta zakon, tega s stebra na Areopagu.

\section{ZAKON}

Možje, slišite, da je bilo temu sodišču na Areopagu, ki je imel starodavno in od nas dodeljeno pravico, da razsoja glede uboja, izrecno zapovedano, naj se ne obsodi za uboj tega, ki bi zasačil prešuštnika pri svoji ženi in izvršil takšno maščevanje. (31) Zakonodajalec je bil v pravilnost takšnega ravnanja v primeru poročenih žensk prepričan tako zelo, da je tudi v primeru priležnic, ki so manjvredne, postavil isto kazen. Povsem jasno je, da bi v primeru poročene ženske izvršil strožjo kazen od te, če bi le lahko. Ker pa zanje zares ni mogel najti sramotnejše kazni od te, je menil, naj bo ista tudi v primeru priležnice. Preberi mi še tale zakon.

\section{$\mathrm{ZAKON}^{16}$}

(32) Možje, slišite, da veleva, naj v primeru, ko bi kdo posilil svobodnega moža ali otroka, ta dolguje dvojno kazen; če pa bi posilil žensko, naj bo v vseh primerih, ko bi ga bilo dovoljeno ubiti, obravnavan na enak način. Možje, zakonodajalec je torej menil, da si tisti, ki se poslužujejo nasilja, zaslužijo manjše kazni od tistih, ki zapeljujejo k dejanju - te je namreč obsodil na smrt, za one pa je določil dvojno kazen. ${ }^{17}$ (33) Verjel je namreč, da ljudi, ki dosegajo svoje s silo, oni, ki jim je bila sila storjena, sovražijo, medtem ko pa tisti ljudje, ki druge zapeljujejo, pokvarijo njihove duše s tem, ko dosežejo, da so tuje žene bolj naklonjene njim kakor pa lastnim možem, da pride celotno gospodarstvo $\mathrm{v}$ njihovo oblast in ni več jasno, čigavi so otroci - moževi ali otroci prešuštnika. $\mathrm{Z}$ ozirom na vse to jim je zakonodajalec določil smrtno kazen. ${ }^{18}$

16 Po tem zakonu je prešuštvo obravnavano kot večji prestopek kakor posilstvo, zato si krivec zasluži tudi večjo - smrtno kazen.

$17 \mathrm{Ni}$ povsem jasno, kaj je mišljeno: morda je moral krivec izplačati določeno vsoto žrtvi, poleg tega pa isti znesek tudi zakladnici ali pa je obtoženi za posilstvo svobodnega plačal dvakratno vsoto, ki je bila določena za posilstvo sužnja. Po tretji razlagi naj bi se vsota računala v odnosu do manjšega prekrška; ker je bilo posilstvo kaznovano strožje, je bila tudi globa potemtakem (dvakrat) večja.

18 Lizija razlikuje med posilstvom, ki je storjeno s silo in brez pristanka žrtve, in prešuštvom, ki vključuje pristanek in je zaradi tega hujši zločin, saj prešuštnik s svojim dejanjem spodkopava 
(34) Možje, mene zakoni niso samo oprostili prekrška, ampak so mi celo velevali, naj si vzamem to pravico; na vas pa je, da poveste, ali kaj veljajo ali ne. (35) Jaz sicer mislim, da vse polis postavljajo zakone, da bi se v primeru zadev, pri katerih smo v zadregi, zatekli k njim in pogledali, kaj nam je storiti. Zakoni namreč v primeru takšnih zadev tistim, ki se jim zgodi krivica, velevajo, naj si vzamejo to pravico. (36) Verjamem, da imate tudi vi enako mnenje: v nasprotnem primeru boste prešuštnikom omogočili takšno brezskrbnost, da boste še tatove spodbudili k zatrjevanju, da so prešuštniki - dobro bodo namreč vedeli, da se jih nihče ne bo dotaknil, če bodo to navedli kot vzrok v svojem primeru in govorili, da so s tem namenom vstopili v tuje hiše. Vsi bodo namreč vedeli, da ni potrebno upoštevati zakonov glede prešuštva, ampak se je potrebno bati le vaših glasov: to ima namreč največjo moč glede vseh zadev v polis.

(37) Premislite, možje! Obtožujejo me, češ da sem onega dne ukazal služabnici, naj pripelje mladeniča. Jaz pa, možje, menim, da bi ravnal pravično ne glede na to, na kateri način bi ujel onega, ki je pokvaril mojo ženo. (38) Če bi vendar ukazal, naj ga pripelje, a bi bile besede le izgovorjene, medtem ko do dejanja ne bi prišlo, ${ }^{19}$ bi res storil krivico. Če pa bi ga, potem ko bi ta dosegel svoje in pogosto hodil v mojo hišo, poskušal ujeti na kakršen koli način že, bi vendarle menil, da ravnam razumno.

(39) Poglejte, kako lažejo tudi glede naslednjega! To boste zlahka spoznali na podlagi tega: kakor sem že prej omenil, možje, imam prijatelja Sostrata, s katerim sva si zelo blizu. Ko me je okoli sončnega zahoda srečal na poti z dežele, se mi je pridružil pri obedu, po lepo preživetem času pa je nemudoma odšel. (40) Najprej, možje, premislite tole: če bi v tisti noči zares snoval kaj proti Eratostenu, kaj bi bilo bolje zame - da večerjam nekje drugje ali da privedem tega človeka, da obeduje $\mathrm{z}$ mano? V tem primeru si oni vendar ne bi upal priti $\mathrm{v}$ hišo! Sicer pa, se vam res zdi, da bi poslal stran tega, ki je obedoval z mano, zato, da bi ostal sam in brez pomoči, namesto da bi mu velel, naj ostane pri meni, da bi skupaj z mano kaznoval prešuštnika? ${ }^{20}$ (41) Dalje, možje, se vam ne zdi bolj verjetno, da bi svoje najbližje poklical podnevi in jim velel, naj se zberejo v hiši nekoga izmed bližnjih prijateljev, kakor pa da bi čakal do zadnjega trenutka in šele ponoči hodil naokoli, ne vedoč, koga bom našel doma in kdo bo kje zunaj?21 Tako pa sem prišel k Harmodiju in še k nekomu drugemu, ki ju ni bilo v mestu (tega pač nisem vedel), pa tudi nekaterih drugih ni bilo doma. S tistimi pa, ki sem jih našel doma, sem šel dalje. (42) Se vam ne zdi, da bi, če bi to res predvidel, to sporočil služabnikom in naznanil prijateljem z

ustaljene moralne norme in ruši družbeni red.

19 Se pravi, če bi si Eratosten in Evfiletova žena izmenjala le ljubezenska pisma, medtem ko do samega dejanja prešuštva ne bi prišlo.

20 S to argumentacijo želi Evfilet spodbiti obtožbo, da je Eratostena zvabil v vnaprej pripravljeno past.

21 Evfilet znova zatrdi, da uboja ni načrtoval, kajti v nasprotnem primeru bi se že prej pozanimal, kdo od njegovih prijateljev je doma in ne bi zapravil dragocenega časa za njihovo iskanje. Ker ni Evfilet ničesar načrtoval, je tvegal, da se mu bo Eratosten izmuznil. 
namenom, da bi lahko kar najbolj varno vstopil (kako naj bi namreč vedel, ali ima tudi oni orožje?) in se maščeval ob prisotnosti številnih prič? Ker pa zares nisem vedel ničesar o tem, kaj se bo zgodilo v oni noči, sem vzel s sabo tiste, ki sem jih lahko. Naj stopijo gor priče teh dogodkov.

\section{PRIČE}

(43) Priče ste slišali, možje: premislite torej sami pri sebi o tej zadevi, medtem ko preiskujete, če je med mano in Eratostenom kdajkoli prišlo do kakšne druge sovražnosti razen te. Odkrili ne boste nobene druge. (44) Kajti proti meni ni vložil ovaduških obtožnic ${ }^{22}$ niti me ni poskusil pregnati iz polis, zasebno me ni tožil in prav tako ni vedel za nobeno zlo dejanje, zaradi katerega bi ga jaz v strahu, da bi kdo za to izvedel, nameraval ubiti. ${ }^{23}$ Četudi bi to izvršil, ne bi imel nobenega upanja na to, da bi od kod dobil denar - nekateri namreč drug drugemu snujejo smrt prav zaradi takšnih razlogov. ${ }^{24}(45)$ Daleč torej od tega, da bi med nama prišlo do zmerjanja ali pivskega prepira ali kakšnega drugega spora, saj človeka še nikdar prej nisem videl, razen prav v tisti noči. Čemu bi potemtakem hotel prestati tolikšno nevarnost, če ne bi bila krivica, ki mi jo je povzročil, zares največja izmed krivic? (46) Čemu sem zagrešil zločin šele potem, ko sem sam sklical priče, ko pa sem imel možnost - če bi ga res nameraval po krivici ubiti - to storiti, ne da bi mi kdo od teh vedel za to ${ }^{25}$

(47) Jaz namreč menim, možje, da to maščevanje ni bilo izvršeno v mojo korist, ampak v korist celotne polis: kajti če bodo tisti posamezniki, ki počenjajo takšne stvari, videli, kakšne nagrade se podeljujejo za takšne prestopke, bodo manj nagnjeni $\mathrm{k}$ hudodelstvom do drugih, sploh če bodo videli, da ste tudi vi takega mnenja. (48) V nasprotnem primeru pa je mnogo boljše izbrisati postavljene zakone in določiti druge - take, ki bodo kaznovali te, ki pazijo na svoje žene, in ki bodo po drugi strani omogočili vso brezskrbnost

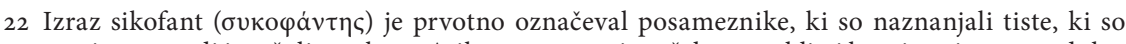
proti prepovedi izvažali smokve z Atike, nato pa se je začela uporabljati kot sinonim za ovaduha, obrekovalca ali goljufa. V zasebnih tožbah so se tega termina posluževali obtoženci, v javnih sodnih postopkih obe stranki, v obeh primerih pa so z uporabo tega izraza namigovali, da gre za brezpredmetno tožbo, katere edini namen je bil izterjati čim več denarja od premožnega meščana ali si pridobiti kako drugo korist.

23 Prvi štirje navedeni motivi za uboj so vsi tako ali drugače vezani na sodne postopke. Pri tem je zassebne tožbe lahko sprožila le tista stran, ki je utrpela krivico, navadno pa so bile tudi kazni bolj mile, medtem ko so bili javni sodni postopki, kjer je šlo za prestopke proti državi, obravnavani veliko bolj strogo, temu primerne pa so bile tudi kazni: obtožencu je grozil zapor, izgon, odvzem državljanskih pravic, zaplemba premoženja, globa, v najslabšem primeru pa celo smrt.

24 Kot peti motiv za uboj Lizija navede pohlep po denarju. Gre za retorični prijem, saj bi bilo absurdno, da bi kdo ubil človeka, od katerega bi hotel terjati denar.

25 Lizija poskuša dodatno podkrepiti trditev, da ni šlo za naklepni uboj. Pravi, da ne bi bilo smiselno sklicati prič, če bi že prej načrtoval maščevanje. Toda po drugi strani so bile priče nujne tudi v primeru, ko bi bil umor načrtovan, saj bi tako lahko potrdile njegovo verzijo zgodbe, česar pa Evfilet seveda ne omeni. Tudi v primeru obtožbe uboja ob ognjišču bi prijatelji lahko pričali v Evfiletovo korist. 
tistim, ki jih želijo prekršiti. ${ }^{26}$ (49) To bi bilo veliko pravičneje, kakor pa da zakoni lovijo v past državljane - in to tisti zakoni, ki sicer velevajo, naj v primeru, če kdo ujame prešuštnika, z njim ravna, kakor hoče. Sodne razprave pa so očitno bolj nevarne za tiste, ki so utrpeli krivico, kakor za one, ki v nasprotju z zakoni onečaščajo tuje žene. (50) Kajti jaz sem sedaj v nevarnosti za življenje, premoženje in vse druge stvari, in to ravno zato, ker sem ubogal zakone te polis. 